\title{
Ischemia Techniques in Nephron-sparing Surgery: A Systematic Review and Meta-Analysis of Surgical, Oncological, and Functional Outcomes
}

\author{
Francesco Greco $^{a, *}$, Riccardo Autorino $^{b}$, Vincenzo Altieri $^{a}$, Steven Campbell $^{c}$, Vincenzo Ficarra $^{d}$, \\ Inderbir Gill ${ }^{e}$, Alexander Kutikov ${ }^{f}$, Alex Mottrie ${ }^{g}$, Vincenzo Mirone ${ }^{h}$, Hendrik van Poppel ${ }^{i}$ \\ ${ }^{a}$ Department of Urology, Humanitas Gavazzeni, Bergamo, Italy; ${ }^{\mathrm{b}}$ Division of Urology, Virginia Commonwealth University, Richmond, VA, USA; ${ }^{\text {Glickman }}$ \\ Urological and Kidney Institute, Cleveland Clinic, Cleveland, OH, USA; ${ }^{\mathrm{d}}$ Department of Human Pathology of Adult and Evolutive Age, University of Messina, \\ Messina, Italy; ${ }^{\mathrm{e}}$ Catherine and Joseph Aresty Department of Urology, Keck School of Medicine, University of Southern California Institute of Urology, Los \\ Angeles, CA, USA; ${ }^{\mathrm{f}}$ Division of Urologic Oncology, Fox Chase Cancer Center, Temple University Health System, Philadelphia, PA, USA; ${ }^{\mathrm{g}}$ Department of Urology, \\ Onze-Lieve-Vrouw Hospital, Aalst, Belgium; ${ }^{\mathrm{h}}$ Department of Urology, Federico II University, Naples, Italy; ${ }^{\mathrm{i}}$ Katholieke Universiteit Leuven, Leuven, Belgium
}

\section{Article info}

Article history:

Accepted October 1, 2018

\section{Associate Editor:}

Stephen Boorjian

\section{Keywords:}

Renal tumor

Nephron-sparing surgery

Ischemia techniques

Outcomes

\begin{abstract}
Context: The optimal ischemia technique at partial nephrectomy (PN) for renal masses is yet to be determined.

Objective: To summarize and analyze the current evidence about surgical, oncological, and functional outcomes after different ischemia techniques (cold, warm, and zero ischemia) at PN.

Evidence acquisition: A computerized systematic literature search was performed by using PubMed (MEDLINE) and Science Direct. Identification and selection of the studies were conducted according to the Preferred Reporting Items for Systematic Reviews and Meta-analysis (PRISMA) criteria. Outcomes of interest were estimated blood loss (EBL), overall complications, positive surgical margins, local tumor recurrence, and renal function preservation. Meta-analysis and forest-plot diagrams were performed. Overall pooled estimates, together with 95\% confidence intervals (CIs), of the incidence of all parameters were obtained using a random effect model (RE-Model) on the log transformed means (MLN), proportion, or standardized mean change, as deemed appropriate.

Evidence synthesis: One hundred and fifty-six studies were included. No clinically meaningful differences were found in terms of EBL after cold (mean: 215.5; 95\% CI: 154.2-276.8 m), warm (mean: 201.8; 95\% CI: 175.0$228.7 \mathrm{ml}$ ), or zero (mean: $261.2 ; 95 \% \mathrm{CI}: 171.0-351.3 \mathrm{ml}$ ) ischemia technique. Overall, postoperative complications were recorded in 14.1\% (95\% CI: 6.7-27.4), 11.1\% (95\% CI: 10.0-12.3), and 9.7\% (95\% CI: 7.7-12.2) of patients after cold, warm, and zero ischemia $(p<0.01)$, respectively. Positive surgical margins were recorded in $4.8 \%(95 \% \mathrm{CI}$ : $1.9-10.9)$, $4.0 \%$ (95\% CI: $3.4-4.8$ ), and 5.6\% (95\% CI: 3.1-9.8) of patients after cold, warm, and zero ischemia $(p<0.01)$, respectively. Local recurrence was recorded in 3.2\% (95\% CI: 1.9-5.2) and 3.1\% (95\% CI: 0.7-11.5) of patients after warm and zero ischemia $(p<0.01)$, respectively. The $\log _{2}$ of estimated glomerular filtration ratio mean changes were-1.37 (95\% Cl:-3.42 to 0.68$),-1.00$ ( -2.04 to 0.03$)$, and- $0.71(-1.15$ to- -0.27$) \mathrm{ml} / \mathrm{min}$ after cold, warm, and zero ischemia, respectively. Low level of evidence, retrospective nature of most of included studies, a high risk of selection bias, and heterogeneity within included studies limited the overall quality of the analysis. Conclusions: The effect of ischemia technique at PN is still debatable and subject to confounding by several factors, namely, patients' selection criteria, surgical technique used, and percentage of functional parenchyma spared during surgery. These confounders bias available evidence and were addressed by only a small part of available studies. Unfortunately, the overall quality of literature evidences and the high risk of selection bias limit the possibility of any causal interpretation about the relationship between the ischemia technique used and surgical, oncological, or functional outcomes. Thus, none of the available ischemia technique could be recommended over the other.

Patient summary: The present analysis shows that none of the available ischemia techniques, namely, cold, warm, or zero ischemia, is universally superior to the others, and other factors play a role in the surgical outcome. (c) 2018 European Association of Urology. Published by Elsevier B.V. All rights reserved.
\end{abstract}

\footnotetext{
* Corresponding author. Department of Urology, Humanitas Gavazzeni, Bergamo, Italy. E-mail address: francesco_greco@ymail.com (F. Greco).
} 


\section{Introduction}

For the surgical treatment of T1 renal tumors, European [1,2] and North American [3,4] guidelines suggest preference for partial nephrectomy (PN) whenever technically and oncologically safe and feasible. The rationale behind this recommendation mainly stems from the evidence of comparable oncological outcomes [5]-improved renal function preservation following PN compared with radical nephrectomy [6,7], as shown in the European Organization for Research and Treatment of Cancer phase 3 prospective randomized controlled trial [8,9], and a non-cancer-related survival benefit [10-14].

An ideal PN should maximize functional and oncological outcomes while minimizing procedure-related complications. Optimization of functional outcomes relies on two main principles: maximizing parenchymal volume preservation and minimizing ischemia-related nephron damage [15-17]. Different ischemia techniques have been developed to reduce the ischemia-related injury [15,16]. During the "open surgery era," surgeons implemented the induction of hypothermia (so-called "cold ischemia") to reduce kidney metabolism during clamping. Others suggested that the warm ischemia time (WIT) should ideally be limited to 20-25 min [18]. More recently, different "off-clamp" or "selective-clamp" techniques have been explored to limit the ischemic kidney injury, and these are generally defined as "zero ischemia" [15,16].

The choice of one ischemia technique over the others is mainly based on surgeon expertise and tumor characteristics. Generally, cold ischemia is preferred when longer ischemia time is expected and when WIT cannot be limited [18]. Instead, in patients with decreased baseline renal function, minimally ischemic and off-clamp PN is preferred. However, concerns about the safety of these techniques were raised [16].

Despite general recommendations about the use of different ischemia techniques in different settings, the current evidence about the outcomes of PN using different ischemia techniques remains controversial. With the aim of filling this gap in the literature, we performed a systematic analysis of the current evidence about surgical, oncological, and functional outcomes after different ischemia techniques.

\section{Evidence acquisition}

\subsection{Literature search and study selection}

The first author (F.G.) established, prior to conducting this systematic review, the selection criteria and research protocol. Thereafter, the protocol was discussed with all the coauthors for approval. The systematic review protocol consisted of five different parts, namely, (1) literature search, (2) study identification and selection, (3) data extraction, (4) study quality assessment, and (5) statistical analysis.

In April 2018, a computerized systematic literature search of papers published up to March 2018 was performed by using PubMed (MEDLINE) and Science Direct. The literature search was carried out adapting the search strategy according to the different research engines. The term "partial nephrectomy" was combined with the keywords "renal cancer," "nephron sparing surgery," "warm ischemia time," "zero ischemia," "clampless," "selective clamp," and "off clamp." The search string used within the PubMed (MEDLINE) engine is specified in the Supplementary material (Search strategy). Additional records on this topic were identified from references cited in the selected manuscripts or in previous review articles on this topic. Literature research was restricted to articles published in the English language. No filters were applied for the date of publication.

The identification and selection of the studies were conducted according to the Preferred Reporting Items for Systematic Reviews and Meta-analysis (PRISMA) criteria and the Population, Intervention, Comparator, Outcomes (PICO) methodology [19,20] (www.prisma-statement.org). PICO was defined as follows: population consisted of patients with renal masses (P) who underwent PN (I). Different ischemia techniques, namely, cold, warm, and zero ischemia, were compared (C). Outcomes of interest were estimated blood loss (EBL), surgical complications, positive margins, local recurrence, and renal function (as assed by the change of estimated glomerular filtration rate [eGFR] after surgery compared with that before; 0 ).

After reviewing the titles and assessing the abstracts to ascertain whether they met the inclusion criteria, full-text articles were read exhaustively. Articles that reported data about at least one of the outcomes of interest were included in our analysis. Studies without original or primary data (ie, reviews, commentaries, and letters) were excluded. Similarly, duplicate or repeated cohorts were excluded from the analyses; moreover, only cohort and case-control or case series studies were included in our analyses. In addition, studies that did not clearly specify the ischemia technique used or had mixed ischemia techniques were excluded. Furthermore, articles that did not report or report renal function in other way than pre- and postoperative eGFR values or were conducted in patients with solitary kidney were excluded. Two authors (F.G. and R.A.) performed independently the literature search and study selection according the aforementioned strategy. A third author (H.V.P.) resolved eventual discrepancies.

\subsection{Data extraction and level of evidence assessment}

For each selected study, the following items were recorded in an Excel (Microsoft, Redmond, WA, USA) sheet: first author's name, year of publication, number of patients, median tumor diameter $(\mathrm{cm})$, median operative time (min), median WIT (min), median ischemia time (min), median EBL ( $\mathrm{ml}$ ), postoperative complications $(n)$, pre- and postoperative eGFR ( $\mathrm{ml} / \mathrm{min})$, local recurrence $(n)$, and margin status $(n)$. Ischemia technique was defined as cold, warm, or zero ischemia. Specifically, all the procedures where any cooling technique was used to limit ischemic damage after artery clamping were considered as cold ischemia PN; otherwise, ischemia was classified as warm [15]. During zero ischemia PN, the hilar vessels were not clamped [21]. Finally, the level of evidence for each outcome was assessed according to the Oxford Centre of Evidence Based Medicine criteria [22]. 


\subsection{Statistical analysis}

Overall pooled estimates, together with 95\% confidence intervals (CIs), of the incidence of all parameters were obtained using a random effect model (RE-Model) on the log transformed means (MLN), proportion, or standardized mean change, as deemed appropriate.

In addition, we aimed to test the effect of different ischemia types within different subgroups of patients. These subgroups were defined according to the median tumor size. Thus, sensitivity analyses tested the effect of different ischemia types within different groups defined according to the tumor size ( $<4$ and $\geq 4 \mathrm{~cm}$ ). Furthermore, we tested the effect of WIT, stratified as $<25$ and $\geq 25 \mathrm{~min}$, on all the outcomes of interest. Finally, we explored the effect of different surgical approaches, namely, open PN (OPN), laparoscopic PN (LPN), and robotic-assisted PN (RAPN), in the different case scenarios. In all the analyses, local recurrences that occurred within $1 \mathrm{yr}$ were included. Moreover, the eGFR change was evaluated at 3 mo.

A funnel plot was used to examine the potential publication bias. Two statistical tests, trim and fill methods, were assessed if there was evidence of a publication bias [23]. The rank correlation test [24] evaluated whether the effect estimates and sampling variances for each study are related. If meta-analyses were smaller than 25 studies Egger's regression test was used [25]. Analyses were performed using the $\mathrm{R}$ software environment for statistical computing and graphics (http://www.r-project.org/). R packages and functions, as well as all the literature references, are noted in the Supplementary material (Search strategy).

\section{Evidence synthesis}

\subsection{Study characteristics}

After the removal of duplicates, our search identified 617 manuscripts. Of these, 291 were full-text screened for eligibility. Finally, 156 studies were included in the current synthesis after exclusion according to the aforementioned strategy [8,21,26-177]. The selection process of the studies is resumed according to the PRISMA flow chart [19] (Supplementary Fig. 1).

Overall, 22626 patients were included in the current study. After stratification according to surgical technique, 1704 patients underwent OPN, 12648 underwent LPN, and 1828 underwent RAPN. Median tumor size ranged from 1.9 to $8.7 \mathrm{~cm}$. After stratification according to the tumor size, 19115 and 2850 patients had renal masses $<4$ and $\geq 4 \mathrm{~cm}$, respectively (Supplementary Table 1 ).

\subsection{Surgical outcomes}

\subsubsection{Estimated blood loss}

Overall, the mean EBL was 218.5 (95\% CI: 189.3-247.7) ml. No clinically meaningful differences were found when cold (mean EBL: $215.5 \mathrm{ml}$ ), warm (mean EBL: $201.8 \mathrm{ml}$ ), or zero (mean EBL: $261.2 \mathrm{ml}$ ) ischemia technique was analyzed in subgroup analyses (Fig. 1).
Similarly, no clinically meaningful differences were found when EBL was examined in patients with renal masses $<4 \mathrm{~cm}$. Specifically, EBL means were 175.0, 185.5, and $192.0 \mathrm{ml}$ after cold, warm, and zero ischemia PN, respectively (Supplementary Fig. 2). Moreover, no clinically meaningful differences were found when EBL was examined in patients with renal masses $\geq 4 \mathrm{~cm}$. Specifically, EBL means were 228.2, 254.6, and $150.0 \mathrm{ml}$ after cold, warm, and zero ischemia PN, respectively (Supplementary Fig. 3).

Moreover, analyses focusing on the effect of WIT on EBL showed that EBL means were 209.6 and $237.1 \mathrm{ml}$ for WIT $<25$ and $\geq 25$ min, respectively (Supplementary Fig. 4 and $5)$. The $\log _{2}$ means of EBL meaningfully varied according to the surgical technique used. Specifically, lower EBL was recorded after RAPN (mean EBL: $147.2 \mathrm{ml}$ ) than after LPN (mean EBL: $192.6 \mathrm{ml}$ ) or OPN (mean EBL: $237.0 \mathrm{ml}$; Supplementary Fig. 6).

Overall, the quality of studies and the study design of included evidence were low according to the Oxford Centre of Evidence Based Medicine criteria (level of evidence 4).

\subsubsection{Postoperative complications}

Overall, $11.0 \%$ (95\% CI: $10.0-12.1 \%$ ) of patients had postoperative complications (Fig. 2). Subgroup analyses for each ischemia technique revealed postoperative complication proportions of $14.1 \%, 11.1 \%$, and $9.7 \%$ for cold, warm, and zero ischemia procedures, respectively (chi-square test on proportion $p<0.01$; Fig. 2). Moreover, sensitivity analyses focusing on patients with renal masses $<4 \mathrm{~cm}$ revealed postoperative complication proportions of $10.5 \%, 10.1 \%$, and $10.4 \%$ for cold, warm, and zero ischemia procedures, respectively (chi-square test on proportion $p<0.01$; Supplementary Fig. 7). Analysis focusing on patients with renal mass $\geq 4 \mathrm{~cm}$ showed postoperative complication proportions of $21.7 \%, 9.7 \%$, and $5.9 \%$ for cold, warm, and zero ischemia procedures, respectively (chi-square test on proportion $p<0.01$; Supplementary Fig. 8).

Moreover, analyses focusing on the effect of WIT on postoperative complications showed that the proportion of patients with complications were $11.9 \%$ and $17.4 \%$ for WIT $<25$ and $\geq 25$ min, respectively (chi-square test on proportion $p<0.01$; Supplementary Fig. 9 and 10).

Proportion of complications varied according to the surgical technique used. Specifically, complications were recorded, respectively, in $12.1 \%, 8.4 \%$, and $10.2 \%$ of patients in whom LPN, OPN, and RAPN were performed (Supplementary Fig. 11).

Overall, the quality of studies and the study design of included evidence were low according to the Oxford Centre of Evidence Based Medicine criteria (level of evidence 4).

\subsection{Oncological outcomes}

\subsubsection{Surgical margins}

Overall, $4.2 \%$ (95\% CI: 3.6-4.9\%) of patients had positive surgical margins (Fig. 3). Subgroup analyses for each ischemia technique revealed positive margin proportions of $4.8 \%, 4.0 \%$, and $5.6 \%$ for cold, warm, and zero ischemia procedures, respectively (chi-square test on proportion 


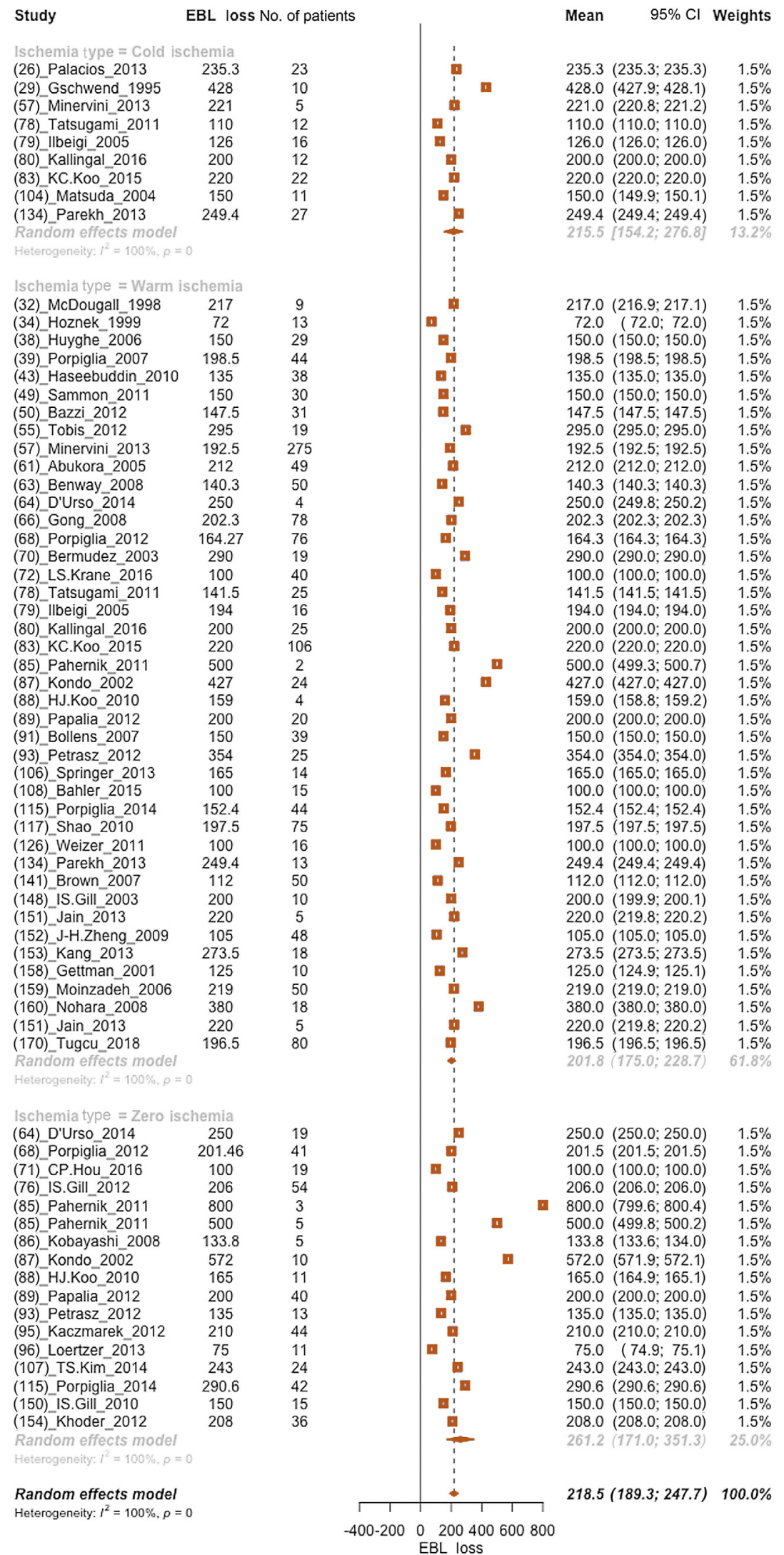

Fig. 1 - Forest plot of meta-analyses of mean estimated blood loss after partial nephrectomy and after stratification according to each ischemia type (cold, warm, and zero ischemia, respectively, from the top to the bottom of the plot). $\mathrm{CI}=$ confidence interval; EBL = estimated blood loss. 


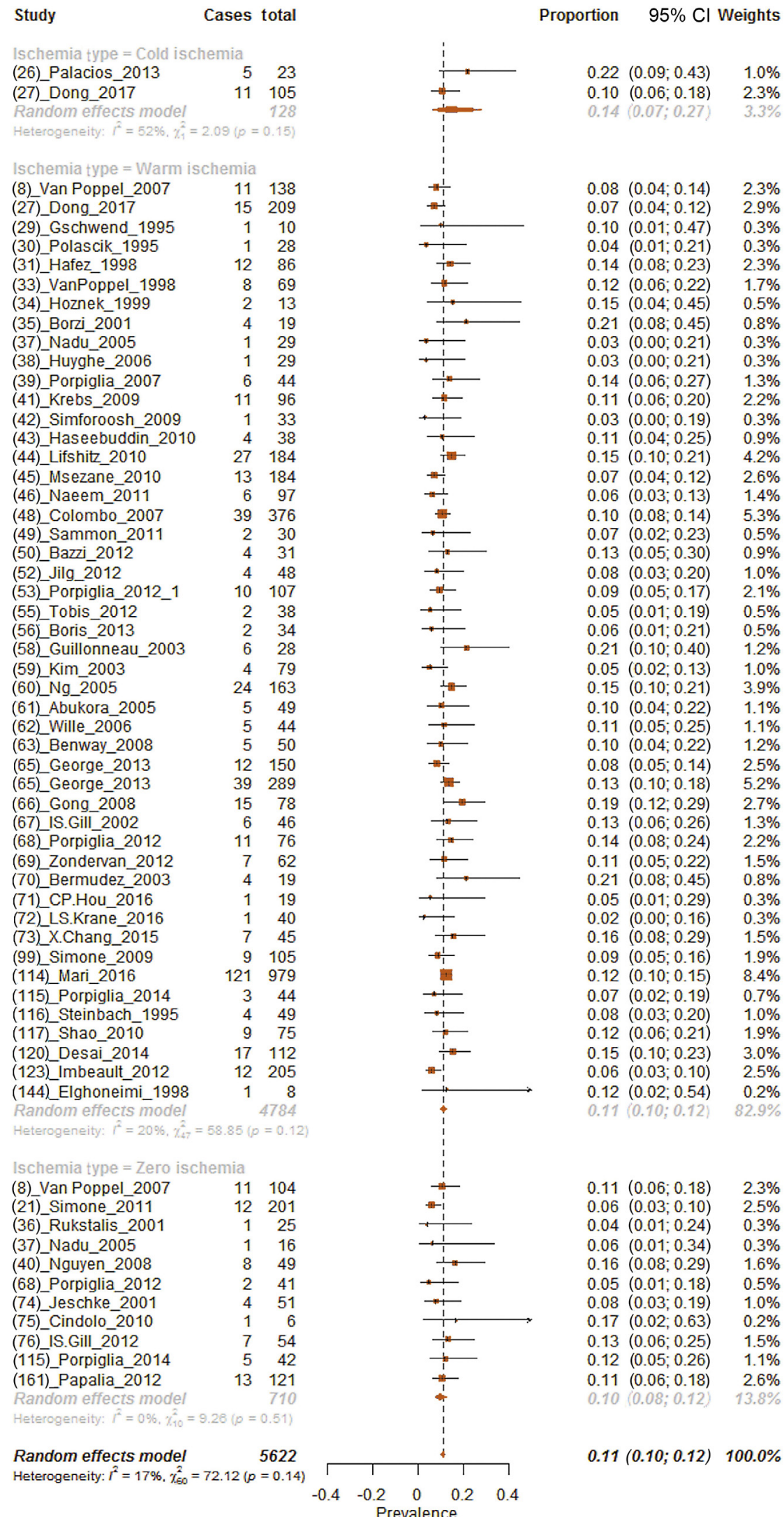

Fig. 2 - Forest plot of meta-analyses of proportions of postoperative complications after partial nephrectomy and after stratification according to each ischemia type (cold, warm, and zero ischemia, respectively, from the top to the bottom of the plot). $\mathrm{CI}=\mathrm{confidence}$ interval. 


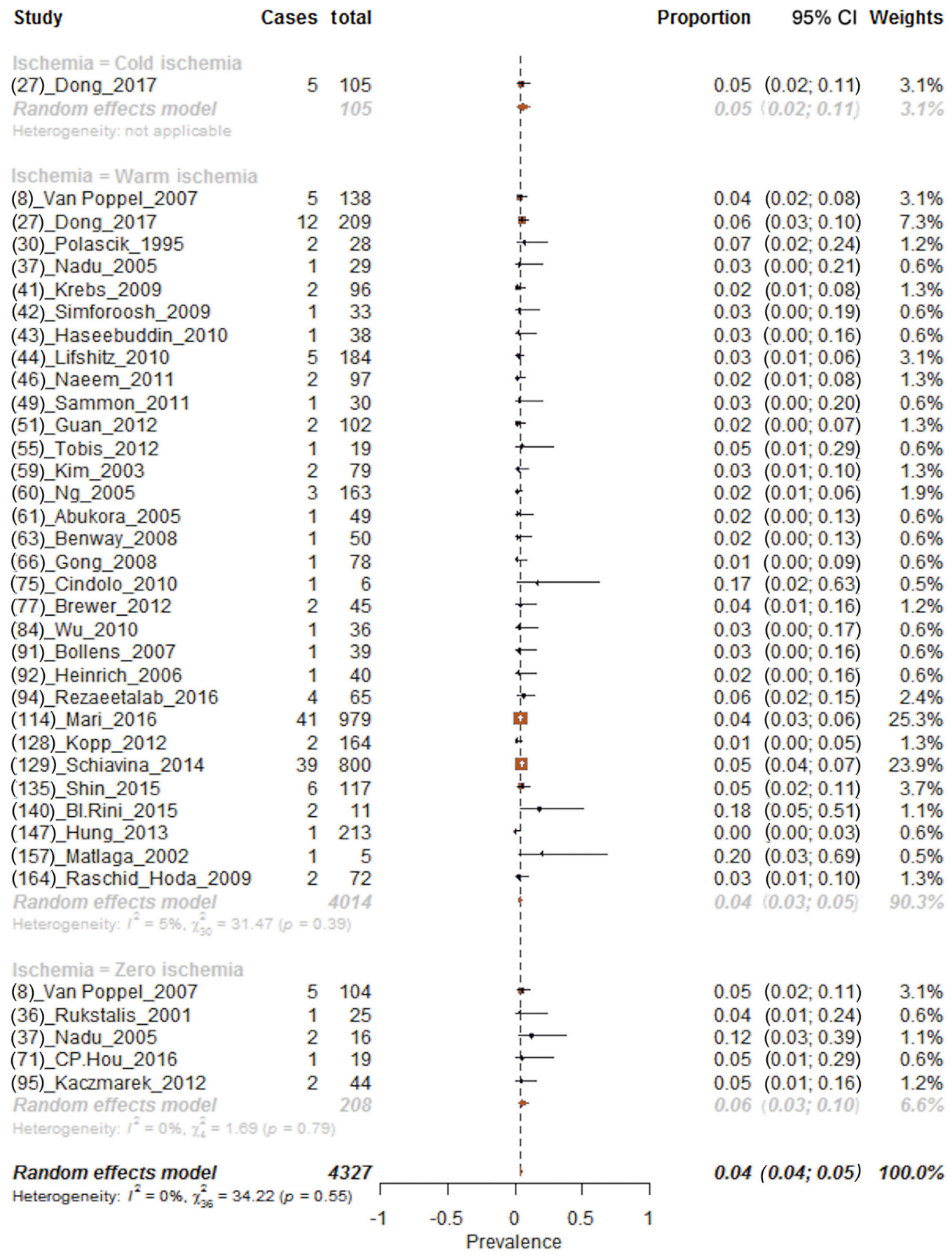

Fig. 3 - Forest plot of meta-analyses of proportions of positive surgical margins after partial nephrectomy and after stratification according to each ischemia type (cold, warm, and zero ischemia, respectively, from the top to the bottom of the plot). $\mathrm{CI}=\mathrm{confidence}$ interval.

$p<0.01$; Fig. 3). In addition, sensitivity analyses focusing on patients with renal masses $<4 \mathrm{~cm}$ revealed positive margin proportions of $4.8 \%, 3.8 \%$, and $5.6 \%$ for, respectively, cold, warm, and zero ischemia procedures (chi-square test on proportion $p<0.01$; Supplementary Fig. 12). Analysis focusing on positive surgical margin proportions after PN in patients with renal masses $\geq 4 \mathrm{~cm}$ could be performed only within patients who underwent warm ischemia PN. Here, positive surgical margins were reported in $5.4 \%$ of patients (Supplementary Fig. 13).
Moreover, analyses focusing on the effect of WIT on positive surgical margins showed that the proportion of patients with positive surgical margins were 5.1\% and $1.9 \%$, respectively, for WIT $<25$ and $\geq 25$ min (chi-square test on proportion $p<0.01$; Supplementary Fig. 14 and 15).

Proportion of positive surgical margins varied according to the surgical technique used. Specifically, positive surgical margins were recorded, respectively, in $4.3 \%, 12.5 \%$, and $3.8 \%$ of patients in whom LPN, OPN, and RAPN were performed (Supplementary Fig. 16). 


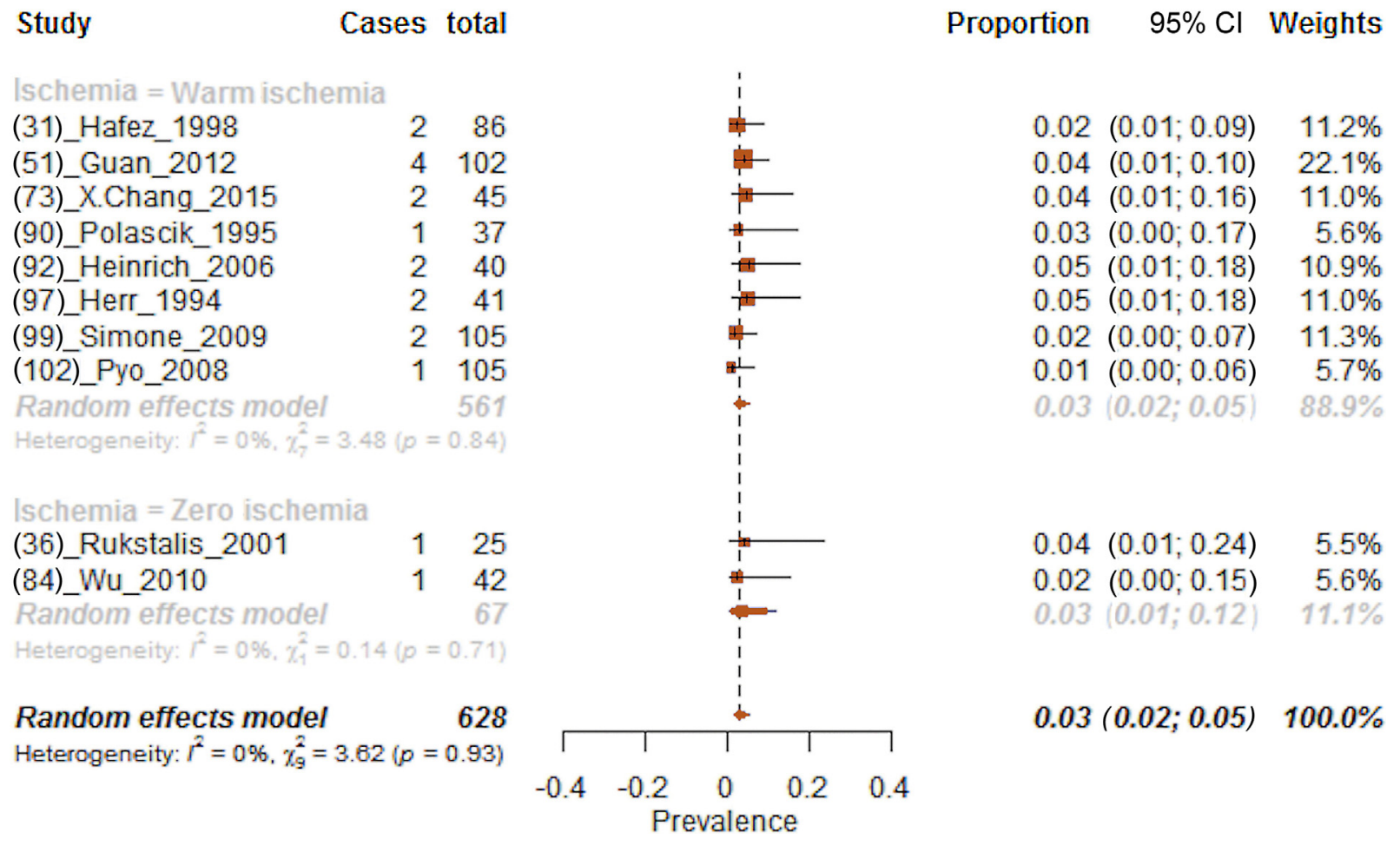

Fig. 4 - Forest plot of meta-analyses of proportions of local recurrence after partial nephrectomy and after stratification according to each ischemia type (warm and zero ischemia, respectively, from the top to the bottom of the plot). $\mathrm{CI}=$ confidence interval.

Overall, the quality of studies and the study design of included evidence were low according to the Oxford Centre of Evidence Based Medicine criteria (level of evidence 4).

\subsubsection{Local recurrence}

The effect of local recurrence was tested according to all the ischemia techniques; however, data availability allowed the inclusion of results after warm and zero ischemia only. Local recurrence was recorded in 3.2\% (95\% CI: $2.0-5.0 \%$ ) of patients (Fig. 4). More specifically, 3.2\% and 3.1\% of patients experienced local recurrence after warm and zero ischemia, respectively. In sensitivity analyses according to renal mass size, the proportions of patients with local recurrence were 1.8 and 3.1, respectively, after warm and zero ischemia in renal masses $<4 \mathrm{~cm}$ (Supplementary Fig. 17). Moreover, proportion of patients with local recurrence was $4.2 \%$ after warm ischemia PN for renal masses $\geq 4 \mathrm{~cm}$ (chi-square test on proportion $p<0.01$; Supplementary Fig. 18).

Furthermore, analyses focusing on the effect of WIT on local recurrence showed that the proportion of patients with local recurrence were $6.9 \%$ and $1.1 \%$ for WIT $<25$ and $\geq 25 \mathrm{~min}$, respectively (chi-square test on proportion $p<0.01$; Supplementary Fig. 19 and 20).

Proportion of local recurrence varied according to the surgical technique used. Specifically, local recurrence was recorded, respectively, in $4.0 \%$ and $6.0 \%$ of patients in whom LPN and RAPN were performed (Supplementary Fig. 21).

Overall, the quality of studies and the study design of included evidence were low according to the Oxford Centre of Evidence Based Medicine criteria (level of evidence 4).

\subsection{Functional outcomes}

Overall, the $\log _{2}$ eGFR standardized mean change was-0.98 (95\% CI:-1.61 to-0.36) $\mathrm{ml} / \mathrm{min}$ (Fig. 5). Subgroup analyses for each technique revealed $\log _{2}$ eGFR standardized mean changes of $-1.37,-1.00$, and $-0.71 \mathrm{ml} / \mathrm{min}$ for cold, warm, and zero ischemia procedures, respectively (Fig. 5).

Sensitivity analyses stratified according to tumor size were also performed; however, these analyses could include only a very small number of studies. Thus, results were not reliable, were biased, and were not included (results not shown).

Moreover, analyses focusing on $\log _{2}$ eGFR standardized mean change according to WIT showed standardized mean changes of-11.65 and-11.63 for, respectively, for WIT $<25$ and $\geq 25$ min (Supplementary Fig. 22 and 23). However, these analyses could include only a small number of studies, and thus no conclusions could be reached based on these results.

The $\log _{2}$ eGFR standardized mean changes were-1.52 and-1.56 after OPN and LPN, respectively (Supplementary Fig. 24).

Overall, the quality of studies and the study design of included evidence were low according to the Oxford Centre of Evidence Based Medicine criteria (level of evidence 4).

\subsection{Publication bias}

We did not find evidence of publication bias upon inspection of funnel plots. Moreover, regression test and 


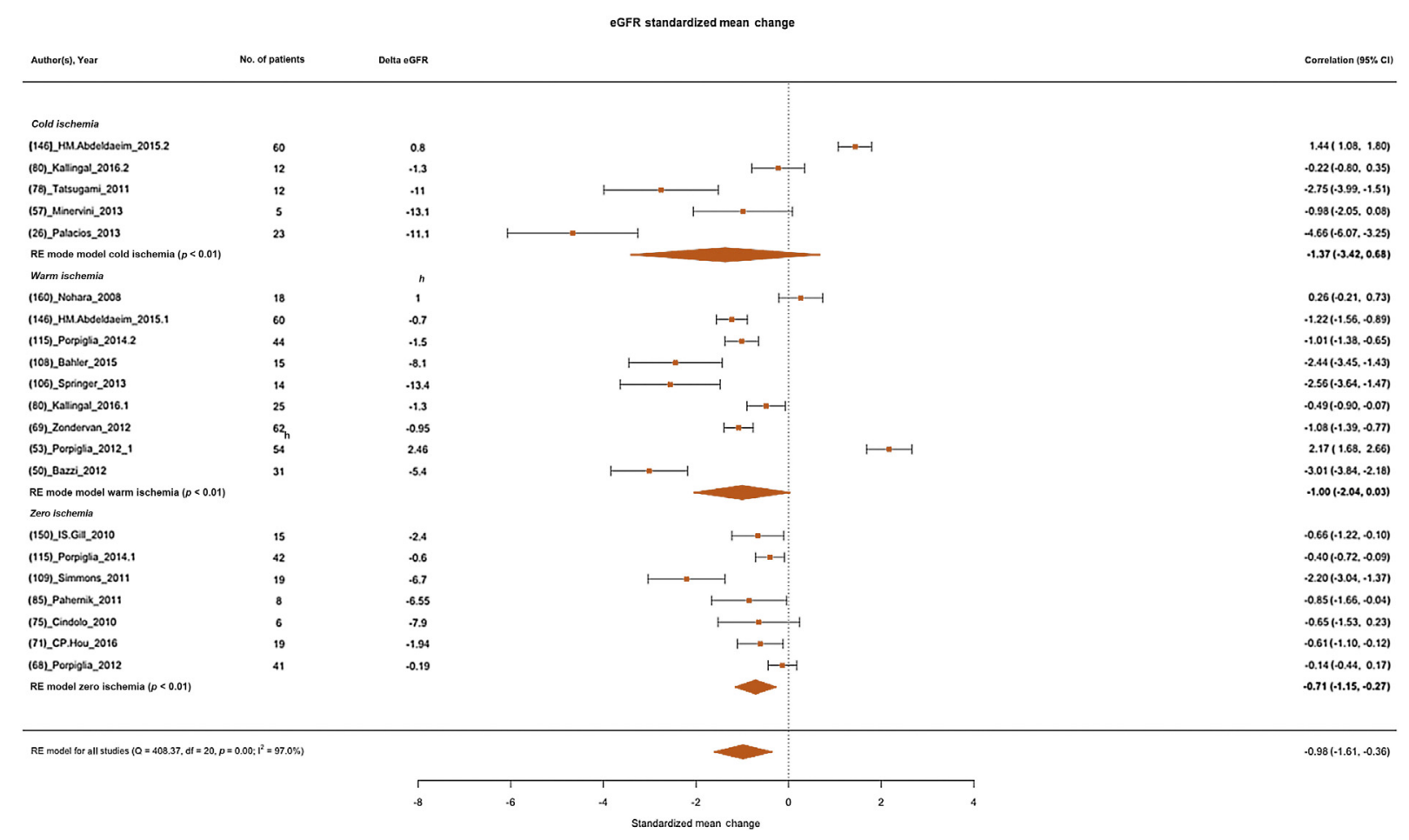

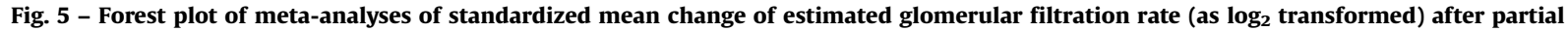
nephrectomy and after stratification according to each ischemia type (cold, warm, and zero ischemia, respectively, from the top to the bottom of the plot). $\mathrm{CI}$ = confidence interval; eGFR = estimated glomerular filtration rate; $\mathrm{RE}=$ random effect.

rank correlation test for funnel plot asymmetry refused the hypothesis of publication bias (all $p>0.05$; Supplementary material, Publication biases).

\subsection{Interpretation of results}

We hypothesized that different ischemia techniques may have a different effect on EBL, surgical complications, positive surgical margins, local tumor recurrence, and renal function preservation. After a systematic review of the literature, we performed a formal meta-analysis of available evidence. Results showed several important findings.

First, results on surgical outcomes showed similar EBL across different surgical techniques, with no clinical meaningful differences. In addition, analyses on postoperative complication proportions showed statistically significant different rates of complications according to different ischemia techniques. Indeed, the complication proportions were higher after cold (14.1\%) than after warm $(11.1 \%)$ or zero $(9.7 \%)$ ischemia. However, these differences may be related to a selection bias. Indeed, complications may be associated with the mass size and not with the ischemia approach by itself. Thus, the stronger driver in postoperative complication rates might be the renal mass size. It seems reasonable to affirm that all these results could be explained considering that cold ischemia is generally indicated for more challenging procedures (eg, large renal masses) that may require longer ischemia time ( $>30 \mathrm{~min}$ ) [178], while the zero ischemia approach is mostly used in very small renal masses. Last but not least, these results derive from only a small number of studies that could be included in our analysis.

Second, our analyses looking at the oncological safety of different ischemia techniques showed higher proportions of positive surgical margins after zero ischemia (5.6\%) than after cold $(4.8 \%)$ or warm $(4.0 \%)$ ischemia. Conversely, similar rates of local recurrence were recorded after zero versus warm ischemia (3.1\% vs 3.4\%). However, when only renal masses $<4 \mathrm{~cm}$ were considered, lower rates of positive surgical margins and local recurrence were recorded after warm ischemia compared with the other techniques.

That said, we still could hypothesize that the ischemia technique by itself may influence the resection technique, resulting in higher positive surgical margins and local recurrence rates. Unfortunately, this hypothesis could not be tested in our analyses because of the inherent selection bias within retrospective series [179], paucity of resection technique standardization (pure enucleation, enucleoresection, or wedge resection) [180], and poor ischemia technique standardization [15,16,181]. Finally, we were not able to verify whether the local recurrences reported were true local recurrences in the resection bed or recurrences elsewhere in the kidney. The aforementioned limitations within our results do not allow inferring of any causality.

Moreover, the impact of positive surgical margins on local recurrence after PN is still controversial, and clinical relevance of a positive surgical margin is still being scrutinized [182]. Indeed, historical multi-institutional analysis showed no effect of positive surgical margins on 
recurrence after multivariable adjustment [183]. More recently, Shah et al. [184] showed that positive surgical margins were associated with an increased recurrence risk. Interestingly, in high-risk patients (pT2-3 and/or Fuhrman grade III-IV) positive surgical margins were still associated with recurrence, while no association was found in a lowrisk patient subgroup.

Third, none of ischemia technique outperforms the other in terms of renal function preservation. Noteworthy, the eGFR standardized mean change was similar throughout different ischemia techniques, and differences may be considered clinically marginal or not meaningful. Nonetheless, these findings should be interpreted cautiously due to the availability of a small number of studies. In particular, sensitivity analyses showed the paucity of studies stratifying according to tumor size and WIT. Moreover, authors would like to emphasize the low level of evidence derived from institutional retrospective studies and the inherent selection bias within those studies. Indeed, each technique has a proper indication and use in current clinical practice. For instance, cold ischemia is generally used for the most difficult cases that are characterized by a larger parenchymal loss due to surgical complexity.

It is of note that the ischemia effect itself on renal parenchyma is still debated [111]. In a recent analysis, Dong et al. [27] showed that cold ischemia was associated with a functional recovery of 99\% versus 92\% recorded after warm ischemia. Moreover, the authors also showed that for each 10 min of warm ischemia, the average renal function loss was about $2.5 \%$. The authors adjusted for the parenchymal mass saved in their analyses. These results suggest a role of ischemia type on renal function preservation, although the impact of functional loss was marginal when compared with the impact of parenchymal mass loss, which is the main determinant of functional outcomes after PN. However, other authors showed different findings. For example, Lee et al. [137] corroborates our findings on a similar detrimental effect of warm ischemia regardless of the WIT. Indeed, the authors showed no significant difference in incidence of chronic kidney disease after PN between two groups defined according to WIT $<30$ or $\geq 30 \mathrm{~min}$.

Parekh et al. [134] prospectively addressed the effect of ischemia on human kidney. The authors performed renal biopsies before, during, and after surgically induced renal clamp ischemia in 40 patients undergoing PN. Results showed a mild transient increase in serum creatinine with a stable level of serum cystatin $C$. Renal functional changes did not correlate with ischemia duration, while renal structural changes were less severe than in animal models. The authors concluded that human kidney may safety tolerate $30-60 \mathrm{~min}$ of controlled clamp ischemia [134]. Authors emphasize the differences with previous reports, which suggested a deleterious effect of ischemia time of $>20-30 \mathrm{~min}$, and justified these differences with other concurrent causes of renal function deterioration, such as tissue damage, sepsis, nephrotoxins, and/or shock [134].

More recently, Zhang et al. [111] evaluated the parenchymal atrophy after clamped PN on 164 patients. The authors evaluated the volume of the renal pole opposite to surgery site before and 4-12 mo after surgery. Their findings showed that median opposite pole volumes were 63.2 and $62.5 \mathrm{~cm}^{3}$, respectively, before and after surgery, with a resulting ratio of 0.99 . The authors also did not find any differences between warm and cold ischemia. The percent of parenchyma preserved may be more important for renal function preservation. Indeed, the percent of parenchymal mass saved during PN seems to strongly correlate with the renal function preservation [28]. Moreover, another source of parenchymal loss is the parenchyma devascularization secondary to the renal reconstruction and renorrhaphy $[135,185]$.

Simmons et al. [105] showed after multivariable adjustment that ischemia time correlated with the nadir of postoperative eGFR but not with the late eGFR. Conversely, preoperative eGFR and the percent functional volume preservation were correlated with late eGFR. These findings were confirmed in a more contemporary analysis by Ginzburg et al. [127]. These investigators also showed a correlation of preoperative eGFR and percent functional volume preservation with eGFR at 6 mo after PN. In the same analysis, the authors also showed the absence of a correlation between eGFR 6 mo after PN and WIT [127].

In summary, current literature evidences are not of enough quality to suggest any clinically meaningful difference between the available ischemia techniques. In consequence, none of the different ischemia techniques seems to outperform the others in regard to any of the examined outcomes. Thus, we are not able to suggest one approach over another. Indeed, several confounders may have affected this result. In particular, postoperative kidney function may be influenced more by the presence of a contralateral functional kidney. Indeed, eGFR evaluates global renal function, while other methodologies such as nuclear renal scan should be adopted when evaluating the single kidney function [186]. In addition, the resection type and the percent of functional parenchyma preserved may have a stronger effect on renal function preservation. Nonetheless, the ischemia technique used may influence both these variables. This consideration may justify the differences in positive surgical margin rates across the different ischemia techniques that may be related to difficulties occurring when surgery is performed without the main artery clamp [15]. Unfortunately, our analysis, as mentioned above, was limited by the small number of studies that relied on resection technique standardization (pure enucleation, enucleoresection, or resection) [180] and/or reported the percent of functional volume preservation.

Other limitations should also be acknowledged. The generalizability of our findings could be limited by the impossibility to perform analyses in a specific subset defined according to the tumor size and some of the outcomes of interest. Despite the efforts of the authors to reduce the variability in the definitions of different ischemia types and make the definitions homogenous during the selection of study phase, a standardized nomenclature of "zero ischemia" is still an unmet need [181]. Moreover, the 
follow-up time when postoperative eGFR was collected varies throughout the included studies. To minimize this variability, we included the first postoperative control when more than one control was reported. Thus, our findings mainly relate to the early postoperative renal function preservation or damage. The reported difference will be even lower and eventually disappear with longer follow-up.

Clinically actionable conclusions from such data can only be reached cautiously, given the marked selection biases inherent to retrospective cohorts. For instance, in some of the analyses, a direct comparison between different ischemia techniques was not possible due to the limited number of studies. Furthermore, differences may be related to a selection bias. Indeed, a high risk of selection bias within retrospective series is possible [179], and in our analyses, we were not able to adjust for all the possible confounders. Moreover, the high heterogeneity existing within the included studies should be taken into consideration before taking making definitive conclusion based on our analyses. Several sources of heterogeneity could be identified; in particular, only a part of the included studies directly addressed the hypothesis that differences may exist in terms of surgical, oncological, or functional outcomes according to the ischemia technique used at PN. In consequence, only a small part of the included studies represent a direct comparison of the three ischemia types. In addition, when this hypothesis was tested, only few of the included studies adjusted for confounding such as the percent of functional parenchyma spared. In summary, the overall quality is biased by the lack of a robust comparative cohort neither prospective nor retrospective. Furthermore, the complications of recording and the time frame of records varied across different studies. Such variability did not allow any standardization and may be a source of bias.

Now, the literature lacks robust randomized clinical trials testing differences between ischemia techniques; thus, none of the included studies is a randomized clinical trial. The latter is a further limitation to the overall quality of our results. In the future, standardized and robust prospective studies are necessary to reach clinically meaningful conclusions. Several ongoing or recently completed randomized clinical trials will analyze the effect of different ischemia types on PN outcomes [187-190]. Hopefully, these studies will answer many other questions that are still open.

\section{Conclusions}

The effect of ischemia technique at PN is still debatable and subject to confounding by several factors, namely, patients' selection criteria, surgical technique used, and percentage of functional parenchyma spared during surgery. These confounders bias available evidence and were addressed by only a small part of the available studies. Unfortunately, the overall quality of literature evidence and the high risk of selection bias limit the possibility of any causal interpretation about the relationship between the ischemia technique used and surgical, oncological, or functional outcomes. Thus, none of the available ischemia techniques could be recommended over the other.
Author contributions: Francesco Greco had full access to all the data in the study and takes responsibility for the integrity of the data and the accuracy of the data analysis.

Study concept and design: Greco.

Acquisition of data: Greco, Autorino, Altieri.

Analysis and interpretation of data: Greco, Mottrie.

Drafting of the manuscript: Greco.

Critical revision of the manuscript for important intellectual content: Campbell, Ficarra, Kutikov.

Statistical analysis: Greco.

Obtaining funding: None.

Administrative, technical, or material support: None.

Supervision: Gill, Mirone, Van Poppel.

Other: None.

Financial disclosures: Francesco Greco certifies that all conflicts of interest, including specific financial interests and relationships and affiliations relevant to the subject matter or materials discussed in the manuscript (eg, employment/affiliation, grants or funding, consultancies, honoraria, stock ownership or options, expert testimony, royalties, or patents filed, received, or pending), are the following: None.

Funding/Support and role of the sponsor: None.

\section{Appendix A. Supplementary data}

Supplementary data associated with this article can be found, in the online version, at https://doi.org/10.1016/j. eururo.2018.10.005.

\section{References}

[1] Ljungberg B, Albiges L, Bex A, et al. EAU guidelines on renal cell carcinoma. 2017 http://uroweb.org/wp-content/uploads/ 10-Renal-Cell-Carcinoma_2017_web.pdf

[2] Escudier B, Porta C, Schmidinger M, et al. Renal cell carcinoma: ESMO Clinical Practice Guidelines for diagnosis, treatment and follow-up. Ann Oncol 2016;27:v58-68.

[3] Motzer RJ, Jonasch E, Agarwal N, et al. NCCN clinical practice guidelines in oncology (NCCN guidelines)-kidney cancer. National Comprehensive Cancer Network.; 2016 https://www.nccn.org/ professionals/physician_gls/PDF/kidney.pdf

[4] Campbell S, Uzzo RG, Allaf ME, et al. Renal mass and localized renal cancer: AUA guideline. J Urol 2017;198:520-9.

[5] Van Poppel H, Da Pozzo L, Albrecht W, et al. A prospective, randomised EORTC intergroup phase 3 study comparing the oncologic outcome of elective nephron-sparing surgery and radical nephrectomy for low-stage renal cell carcinoma. Eur Urol 2011;59:543-52.

[6] Zabell JR, Wu J, Suk-Ouichai C, Campbell SC. Renal ischemia and functional outcomes following partial nephrectomy. Urol Clin North Am 2017;44:243-55.

[7] Patel HD, Pierorazio PM, Johnson MH, et al. Renal functional outcomes after surgery, ablation, and active surveillance of localized renal tumors: a systematic review and meta-analysis. Clin J Am Soc Nephrol 2017;12:1057-69.

[8] Van Poppel H, Da Pozzo L, Albrecht W, et al. A prospective randomized EORTC intergroup phase 3 study comparing the complications of elective nephron-sparing surgery and radical nephrectomy for low-stage renal cell carcinoma. Eur Urol 2007;51:1606-15.

[9] Scosyrev E, Messing EM, Sylvester R, Campbell S, Van Poppel H. Renal function after nephron-sparing surgery versus radical ne- 
phrectomy: results from EORTC randomized trial 30904. Eur Urol 2014;65:372-7.

[10] Sun M, Trinh Q-D, Bianchi M, et al. A non-cancer-related survival benefit is associated with partial nephrectomy. Eur Urol 2012;61:725-31.

[11] Bianchi M, Gandaglia G, Trinh Q-D, et al. A population-based competing-risks analysis of survival after nephrectomy for renal cell carcinoma. Urol Oncol Semin Orig Investig 2014;32, 46.e1-e7.

[12] Go AS, Chertow GM, Fan D, McCulloch CE, Hsu C. Chronic kidney disease and the risks of death, cardiovascular events, and hospitalization. N Engl J Med 2004;351:1296-305.

[13] Weight CJ, Lieser G, Larson BT, et al. Partial nephrectomy is associated with improved overall survival compared to radical nephrectomy in patients with unanticipated benign renal tumours. Eur Urol 2010;58:293-8.

[14] Marchioni M, Preisser F, Bandini M, et al. Comparison of partial versus radical nephrectomy effect on other-cause mortality, cancer-specific mortality, and 30-day mortality in patients older than 75 years. Eur Urol Focus. In press. https://doi.org/10.1016/j.euf.2018.01.007.

[15] Klatte T, Ficarra V, Gratzke C, et al. A literature review of renal surgical anatomy and surgical strategies for partial nephrectomy. Eur Urol 2015;68:980-92.

[16] Simone G, Gill IS, Mottrie A, et al. Indications, techniques, outcomes, and limitations for minimally ischemic and off-clamp partial nephrectomy: a systematic review of the literature. Eur Urol 2015;68:632-40.

[17] Mir MC, Ercole C, Takagi T, et al. Decline in renal function after partial nephrectomy: etiology and prevention. J Urol 2015;193:1889-98.

[18] Volpe A, Blute ML, Ficarra V, et al. Renal ischemia and function after partial nephrectomy: a collaborative review of the literature. Eur Urol 2015;68:61-74.

[19] Moher D, Liberati A, Tetzlaff J, Altman DG. Preferred reporting items for systematic reviews and meta-analyses: the PRISMA statement. Int J Surg 2010;8:336-41.

[20] Shamseer L, Moher D, Clarke M, et al. Preferred reporting items for systematic review and meta-analysis protocols (PRISMA-P) 2015: elaboration and explanation. BMJ 2015;349:g7647.

[21] Simone G, Papalia R, Guaglianone S, Carpanese L, Gallucci M. Zero ischemia laparoscopic partial nephrectomy after superselective transarterial tumor embolization for tumors with moderate nephrometry score: long-term results of a single-center experience. J Endourol 2011;25:1443-6.

[22] OCEBM Levels of Evidence Working Group. OCEBM levels of evidence. CEBM; 2016 In: http://www.cebm.net/blog//05/01/ ocebm-levels-of-evidence/

[23] Duval S, Tweedie R. Trim and fill: a simple funnel-plot-based method of testing and adjusting for publication bias in metaanalysis. Biometrics 2000;56:455-63.

[24] Begg CB, Mazumdar M. Operating characteristics of a rank correlation test for publication bias. Biometrics 1994;50:1088-101.

[25] Egger M, Smith GD, Schneider M, Minder C. Bias in meta-analysis detected by a simple, graphical test. BMJ 1997;315:629-34.

[26] Palacios DA, McDonald M, Miyake M, Rosser CJ. Pilot study comparing the two hemostatic agents in patients undergoing partial nephrectomy. BMC Res Notes 2013;6:399.

[27] Dong W, Wu J, Suk-Ouichai C, et al. Ischemia and functional recovery from partial nephrectomy: refined perspectives. Eur Urol Focus 2017. In press. https://doi.org/10.1016/j.euf.02.001

[28] Dong W, Zhang Z, Zhao J, et al. Excised parenchymal mass during partial nephrectomy: functional implications. Urology 2017;103:129-35.

[29] Gschwend JE, De Petriconi R, Maier S, Kleinschmidt K, Hautmann RE. Continuous in situ cold perfusion with histidine tryptophan ketoglutarate solution in nephron sparing surgery for renal tumors. J Urol 1995;154:1307-11.

[30] Polascik TJ, Pound CR, Meng MV, Partin AW, Marshall FF. Partial nephrectomy: technique complications and pathological findings. J Urol 1995;154:1312-8.

[31] Hafez KS, Novick AC, Butler BP. Management of small solitary unilateral renal cell carcinomas: impact of central versus peripheral tumor location. J Urol 1998;159:1156-60.

[32] McDougall EM, Elbahnasy AM, Clayman RV. Laparoscopic wedge resection and partial nephrectomy - the Washington University experience and review of the literature. JSLS 1998;2:15.

[33] Van Poppel H, Bamelis B, Oyen R, Baert L. Partial nephrectomy for renal cell carcinoma can achieve long-term tumor control. J Urol 1998;160:674-8.

[34] Hoznek A, Salomon L, Antiphon P, et al. Partial nephrectomy with retroperitoneal laparoscopy. J Urol 1999;162:1922-96.

[35] Borzi PA. A comparison of the lateral and posterior retroperitoneoscopic approach for complete and partial nephroureterectomy in children. BJU Int 2001;87:517-20.

[36] Rukstalis DB, Khorsandi M, Garcia FU, Hoenig DM, Cohen JK. Clinical experience with open renal cryoablation. Urology 2001;57:34-9.

[37] Nadu A, Kitrey N, Mor Y, Golomb J, Ramon J. Laparoscopic partial nephrectomy: is it advantageous and safe to clamp the renal artery? Urology 2005;66:279-82.

[38] Huyghe E, Nohra J, Leobon B, et al. Open partial nephrectomy with selective renal parenchymal control: a new reliable clamp. Urology 2006;68:658-60.

[39] Porpiglia F, Renard J, Billia M, Morra I, Terrone C, Scarpa RM. Biological glues and collagen fleece for hemostasis during laparoscopic partial nephrectomy: technique and results of prospective study. J Endourol 2007;21:423-8.

[40] Nguyen MM, Gill IS. Halving ischemia time during laparoscopic partial nephrectomy. J Urol 2008;179:627-32.

[41] Krebs RK, Andreoni C, Khalil W, Ortiz V. Contemporary different patterns of indications and outcomes for the surgical management of renal tumors in an academic center. J Endourol 2009;23:1903-7.

[42] Simforoosh N, Noor-Alizadeh A, Tabibi A, et al. Bolsterless laparoscopic partial nephrectomy: a simplification of the technique. J Endourol 2009;23:965-9.

[43] Haseebuddin M, Benway BM, Cabello JM, Bhayani SB. Robotassisted partial nephrectomy: evaluation of learning curve for an experienced renal surgeon. J Endourol 2010;24:57-61.

[44] Lifshitz DA, Shikanov SA, Deklaj T, Katz MH, Zorn KC, Shalhav AL. Laparoscopic partial nephrectomy for tumors larger than $4 \mathrm{~cm}$ : a comparative study. J Endourol 2010;24:49-55.

[45] Msezane L, Chang A, Shikanov S, et al. Laparoscopic nephronsparing surgery in the management of angiomyolipoma: a single center experience. J Endourol 2010;24:583-7.

[46] Naeem N, Petros F, Sukumar S, et al. Robot-assisted partial nephrectomy in obese patients. J Endourol 2011;25:101-5.

[47] Romero FR, Rais-Bahrami S, Muntener M, Brito FAR, Jarrett TW, Kavoussi LR. Laparoscopic partial nephrectomy in obese and nonobese patients: comparison with open surgery. Urology 2008;71:806-9.

[48] Colombo JR, Haber G-P, Aron M, Xu M, Gill IS. Laparoscopic partial nephrectomy in obese patients. Urology 2007;69:44-8.

[49] Sammon J, Petros F, Sukumar S, et al. Barbed suture for renorrhaphy during robot-assisted partial nephrectomy. J Endourol 2011;25:529-33.

[50] Bazzi WM, Stroup SP, Kopp RP, Cohen SA, Sakamoto K, Derweesh IH. Comparison of laparoendoscopic single-site and multiport laparoscopic radical and partial nephrectomy: a prospective, nonrandomized study. Urology 2012;80:1039-45. 
[51] Guan W, Bai J, Liu J, et al. Microwave ablation versus partial nephrectomy for small renal tumors: Intermediate-term results. J Surg Oncol 2012;106:316-21.

[52] Jilg CA, Neumann HPH, Gläsker S, et al. Nephron sparing surgery in von Hippel-Lindau associated renal cell carcinoma; clinicopathological long-term follow-up. Fam Cancer 2012;11:387-94.

[53] Porpiglia F, Fiori C, Bertolo R, et al. Long-term functional evaluation of the treated kidney in a prospective series of patients who underwent laparoscopic partial nephrectomy for small renal tumors. Eur Urol 2012;62:130-5.

[54] Porpiglia F, Fiori C, Bertolo R, et al. The effects of warm ischaemia time on renal function after laparoscopic partial nephrectomy in patients with normal contralateral kidney. World J Urol 2012;30:257-63.

[55] Tobis S, Knopf JK, Silvers C, et al. Robot-assisted and laparoscopic partial nephrectomy with near infrared fluorescence imaging. J Endourol 2012;26:797-802.

[56] Boris RS, Gupta GN, Benson JS, Linehan WM, Pinto PA, Bratslavsky G. Feasibility and outcomes of laparoscopic renal intervention after prior open ipsilateral retroperitoneal surgery. J Endourol 2013;27:196-201.

[57] Minervini A, Siena G, Antonelli A, Bianchi G, et al. Open versus laparoscopic partial nephrectomy for clinical T1a renal masses: a matched-pair comparison of 280 patients with TRIFECTA outcomes (RECORd Project). World J Urol 2014;32:257-63.

[58] Guillonneau B, Bermudez H, Gholami S, et al. Laparoscopic partial nephrectomy for renal tumor: single center experience comparing clamping and no clamping techniques of the renal vasculature. J Urol 2003;169:483-6.

[59] Kim FJ, Rha KH, Hernandez F, Jarrett TW, Pinto PA, Kavoussi LR. Laparoscopic radical versus partial nephrectomy: assessment of complications. J Urol 2003;170:408-11.

[60] Ng CS, Gill IS, Ramani AP, et al. Transperitoneal versus retroperitoneal laparoscopic partial nephrectomy: patient selection and perioperative outcomes. J Urol 2005;174:846-9.

[61] Abukora F, Nambirajan T, Albqami N, et al. Laparoscopic nephron sparing surgery: evolution in a decade. Eur Urol 2005;47:488-93.

[62] Wille AH, Tüllmann M, Roigas J, Loening SA, Deger S. Laparoscopic partial nephrectomy in renal cell cancer-results and reproducibility by different surgeons in a high volume laparoscopic center. Eur Urol 2006;49:337-43.

[63] Benway BM, Bhayani SB, Rogers CG, et al. Robot assisted partial nephrectomy versus laparoscopic partial nephrectomy for renal tumors: a multi-institutional analysis of perioperative outcomes. J Urol 2009;182:866-72.

[64] D'Urso L, Simone G, Rosso R, et al. Benefits and shortcomings of superselective transarterial embolization of renal tumors before zero ischemia laparoscopic partial nephrectomy. Eur J Surg Oncol 2014;40:1731-7.

[65] George AK, Herati AS, Srinivasan AK, et al. Perioperative outcomes of off-clamp vs complete hilar control laparoscopic partial nephrectomy. BJU Int 2013;111:E235-41.

[66] Gong EM, Zorn KC, Orvieto MA, Lucioni A, Msezane LP, Shalhav AL. Artery-only occlusion may provide superior renal preservation during laparoscopic partial nephrectomy. Urology 2008;72:843-6.

[67] Gill IS, Desai MM, Kaouk JH, et al. Laparoscopic partial nephrectomy for renal tumor: duplicating open surgical techniques. J Urol 2002;167:469-76.

[68] Porpiglia F, Bertolo R, Morra I, Fiori C. Clampless laparoscopic partial nephrectomy: a step towards a harmless nephron-sparing surgery? Int Braz J Urol 2012;38:480-8.

[69] Zondervan PJ, Gozen AS, Opondo D, Rassweiler JJ, de la Rosette JJ, Laguna MP. Partial nephrectomy: Is there an advantage of the selfretaining barbed suture in the perioperative period?. A matched case-control comparison. World J Urol 2012;30:659-64.
[70] Bermudez H, Guillonneau B, Gupta R, et al. Initial experience in laparoscopic partial nephrectomy for renal tumor with clamping of renal vessels. J Endourol 2003;17:373-8.

[71] Hou C-P, Lin Y-H, Hsu Y-C, Chen C-L, Chang P-L, Tsui K-H. Using a harmonic scalpel "drilling and clamping" method to implement zero ischemic robotic-assisted partial nephrectomy. Medicine (Baltimore) 2016;95:e2349

[72] Krane LS, Peyton CC, Olympio MA, Hemal AK. A randomized double blinded placebo controlled trial of sildenafil for renoprotection prior to hilar clamping in patients undergoing robotic assisted laparoscopic partial nephrectomy: sildenafil in partial nephrectomy. J Surg Oncol 2016;114:785-8.

[73] Chang X, Liu T, Zhang F, et al. Radiofrequency ablation versus partial nephrectomy for clinical t1a renal-cell carcinoma: longterm clinical and oncologic outcomes based on a propensity score analysis. J Endourol 2015;29:518-25.

[74] Jeschke K, Peschel R, Wakonig J, Schellander L, Bartsch G, Henning K. Laparoscopic nephron-sparing surgery for renal tumors. Urology 2001;58:688-92.

[75] Cindolo L, Berardinelli F, Gidaro S, Schips L. Laparoendoscopic single-site partial nephrectomy without ischemia. J Endourol 2010;24:1997-2002.

[76] Gill IS, Patil MB, de Castro Abreu AL, et al. Zero ischemia anatomical partial nephrectomy: a novel approach. J Urol 2012;187:807-15.

[77] Brewer K, O'Malley RL, Hayn M, et al. Perioperative and renal function outcomes of minimally invasive partial nephrectomy for $\mathrm{T}_{1 \mathrm{~b}}$ and $\mathrm{T}_{2 \mathrm{a}}$ kidney tumors. J Endourol 2012;26:244-8.

[78] Tatsugami K, Eto M, Yokomizo A, et al. Impact of cold and warm ischemia on postoperative recovery of affected renal function after partial nephrectomy. J Endourol 2011;25:869-73.

[79] Ilbeigi P, Ahmed M, Szobota J, Munver R, Sawczuk IS. Open partial nephrectomy using saline-enhanced monopolar radiofrequency device: evaluation of novel surgical technique with TissueLink DS3.0 Dissecting Sealer. Urology 2005;65:578-82.

[80] Kallingal GJS, Weinberg JM, Reis IM, Nehra A, Venkatachalam MA, Parekh DJ. Long-term response to renal ischaemia in the human kidney after partial nephrectomy: results from a prospective clinical trial. BJU Int 2016;117:766-74.

[81] Lane BR, Gill IS, Fergany AF, Larson BT, Campbell SC. Limited warm ischemia during elective partial nephrectomy has only a marginal impact on renal functional outcomes. J Urol 2011;185:1598-603.

[82] Bessede T, Bigot P, Bernhard J-C, et al. Are warm ischemia and ischemia time still predictive factors of poor renal function after partial nephrectomy in the setting of elective indication? World J Urol 2015;33:11-5.

[83] Koo KC, Hong JH, Lee HS, et al. Accuracy of urinary neutrophil gelatinase-associated lipocalin in quantifying acute kidney injury after partial nephrectomy in patients with normal contralateral kidney. PLoS One 2015; 10, e0133675.

[84] Wu SD, Viprakasit DP, Cashy J, Smith ND, Perry KT, Nadler RB. Radiofrequency ablation-assisted robotic laparoscopic partial nephrectomy without renal hilar vessel clamping versus laparoscopic partial nephrectomy: a comparison of perioperative outcomes. J Endourol 2010;24:385-91.

[85] Pahernik S, Reiter M, Hatiboglu G, et al. Combining open and laparoscopic surgery for partial nephrectomy. J Endourol 2011;25:821-4.

[86] Kobayashi Y, Saika T, Manabe D, Nasu Y, Kumon H. The benefits of clamping the renal artery in laparoscopic partial nephrectomy. Acta Med Okayama 2008;62:269-73.

[87] Kondo T, Nakazawa H, Ito F, et al. Impact of arterial occlusion during partial nephrectomy on residual renal function: an evaluation with $99 \mathrm{~m}$ technetium-dimercaptosuccinic acid scintigraphy. Int J Urol 2002;9:435-40. 
[88] Koo HJ, Lee DH, Kim IY. Renal hilar control during laparoscopic partial nephrectomy: to clamp or not to clamp. J Endourol 2010;24:1283-7.

[89] Papalia R, Simone G, Ferriero M, et al. Laparoscopic and robotic partial nephrectomy with controlled hypotensive anesthesia to avoid hilar clamping: feasibility, safety and perioperative functional outcomes. J Urol 2012;187:1190-4.

[90] Polascik TJ, Meng MV, Epstein JI, Marshall FF. Intraoperative sonography for the evaluation and management of renal tumors: experience with 100 patients. J Urol 1995;154:1676-80.

[91] Bollens R, Rosenblatt A, Espinoza BP, et al. Laparoscopic partial nephrectomy with "on-demand" clamping reduces warm ischemia time. Eur Urol 2007;52:804-10.

[92] Heinrich E, Egner T, Noe M, Schiefelbein F, Schoen G. Organpreserving endoscopic kidney cancer resection. Eur Urol 2006;50:732-7.

[93] Petrasz P, Słojewski M, Sikorski A. Impact of "non-clamping technique" on intra- and postoperative course after laparoscopic partial nephrectomy. Videosurgery Miniinvasive Tech 2012;7:275-9.

[94] Rezaeetalab GH, Karami H, Dadkhah F, Simforoosh N, Shakhssalim N. Laparoscopic versus open partial nephrectomy for stage T1a of renal tumors. Urol J 2016;13:2903-7.

[95] Kaczmarek BF, Tanagho YS, Hillyer SP, et al. Off-clamp robotassisted partial nephrectomy preserves renal function: a multiinstitutional propensity score analysis. Eur Urol 2013;64:988-93.

[96] Loertzer H, Strauß A, Ringert RH, Schneider P. Laser-supported partial laparoscopic nephrectomy for renal cell carcinoma without ischaemia time. BMC Urol 2013;13:31.

[97] Herr HW. Partial nephrectomy for incidental renal cell carcinoma. BJU Int 1994;74:431-3.

[98] Fergany AF, Hafez KS, Novick AC. Long-term results of nephron sparing surgery for localized renal cell carcinoma: 10-year followup. J Urol 2000;163:442-5.

[99] Simone G, Papalia R, Guaglianone S, Forestiere E, Gallucci M. Preoperative superselective transarterial embolization in laparoscopic partial nephrectomy: technique, oncologic, and functional outcomes. J Endourol 2009;23:1473-8.

[100] Lista G, Buffi NM, Lughezzani G, et al. Margin, ischemia, and complications system to report perioperative outcomes of robotic partial nephrectomy: a European Multicenter Observational Study (EMOS Project). Urology 2015;85:589-95.

[101] van Oostenbrugge TJ, Kroeze SGC, Bosch JLHR, van Melick HHE. The blind spots in follow-up after nephrectomy or nephron-sparing surgery for localized renal cell carcinoma. World J Urol 2015;33:881-7.

[102] Pyo P, Chen A, Grasso M. Retroperitoneal laparoscopic partial nephrectomy: surgical experience and outcomes. J Urol 2008;180:1279-83.

[103] Shinohara N, Nonomura K, Harabayashi T, Togashi M, Nagamori S, Koyanagi T. Nephron sparing surgery for renal cell carcinoma in von Hippel-Lindau disease. J Urol 1995;154:2016-9.

[104] Matsuda T, Nakagawa M, Oguchi N, et al. Retroperitoneoscopic partial nephrectomy with transient occlusion of renal artery for treatment of small renal tumors. Urology 2004;64:26-30.

[105] Simmons MN, Fergany AF, Campbell SC. Effect of parenchymal volume preservation on kidney function after partial nephrectomy. J Urol 2011;186:405-10.

[106] Springer C, Veneziano D, Wimpissinger F, Inferrera A, Fornara P, Greco F. Clampless laparoendoscopic single-site partial nephrectomy for renal cancer with low PADUA score: technique and surgical outcomes. BJU Int 2013;111:1091-8.

[107] Kim TS, Oh JH, Rhew HY. Off-clamp, non-renorrhaphy" laparoscopic partial nephrectomy with perirenal fat and Gerota's fascia reapproximation: initial experience and perioperative outcomes. J Laparoendosc Adv Surg Tech 2014;24:339-44.

[108] Bahler CD, Dube HT, Flynn KJ, et al. Feasibility of omitting cortical renorrhaphy during robot-assisted partial nephrectomy: a matched analysis. J Endourol 2015;29:548-55.

[109] Simmons MN, Hillyer SP, Lee BH, Fergany AF, Kaouk J, Campbell SC. Functional recovery after partial nephrectomy: effects of volume loss and ischemic injury. J Urol 2012;187:1667-73.

[110] Zhao J, Zhang Z, Dong W, et al. Preoperative prediction and postoperative surgeon assessment of volume preservation associated with partial nephrectomy: comparison with measured volume preservation. Urology 2016;93:124-9.

[111] Zhang Z, Ercole CE, Remer EM, et al. Analysis of atrophy after clamped partial nephrectomy and potential impact of ischemia. Urology 2015;85:1417-23.

[112] Schauer I, Theimer O, Klatte T, Waldert M, Klingler H-C, Margreiter M. Use of self-retaining barbed sutures decreases cold ischemia time in open nephron-sparing surgery. Wien Klin Wochenschr 2014;126:329-34.

[113] Minervini A, Vittori G, Antonelli A, et al. Open versus robotic-assisted partial nephrectomy: a multicenter comparison study of perioperative results and complications. World J Urol 2014;32:287-93.

[114] Mari A, Antonelli A, Bertolo R, et al. Predictive factors of overall and major postoperative complications after partial nephrectomy: results from a multicenter prospective study (the RECORd 1 project). Eur J Surg Oncol J Eur Soc Surg Oncol Br Assoc Surg Oncol 2017;43:823-30.

[115] Porpiglia F, Bertolo R, Amparore D, et al. Evaluation of functional outcomes after laparoscopic partial nephrectomy using renal scintigraphy: clamped vs clampless technique. BJU Int 2015;115:606-12.

[116] Steinbach F, Novick AC, Zincke H, et al. Treatment of renal cell carcinoma in von Hippel-Lindau disease: a multicenter study. J Urol 1995;153:1812-6.

[117] Shao P, Qin C, Yin C, et al. Laparoscopic partial nephrectomy with segmental renal artery clamping: technique and clinical outcomes. Eur Urol 2011;59:849-55.

[118] Benway BM, Wang AJ, Cabello JM, Bhayani SB. Robotic partial nephrectomy with sliding-clip renorrhaphy: technique and outcomes. Eur Urol 2009;55:592-9.

[119] Sandberg JM, Krane LS, Hemal AK. A nonrandomized prospective comparison of robotic-assisted partial nephrectomy in the elderly to a younger cohort: an analysis of 339 patients with intermediateterm follow-up. Urology 2014;84:838-43.

[120] Desai MM, de Castro Abreu AL, Leslie S, et al. Robotic partial nephrectomy with superselective versus main artery clamping: a retrospective comparison. Eur Urol 2014;66:713-9.

[121] Li M, Gao Y, Cheng J, et al. Diameter-axial-polar nephrometry is predictive of surgical outcomes following partial nephrectomy. Medicine (Baltimore) 2015;94, e1228.

[122] Haber G-P, Gill IS. Laparoscopic partial nephrectomy: contemporary technique and outcomes. Eur Urol 2006;49:660-5.

[123] Imbeault A, Pouliot F, Finley DS, Shuch B, Dujardin T. Prospective study comparing two techniques of renal clamping in laparoscopic partial nephrectomy: impact on perioperative parameters. J Endourol 2012;26:509-14.

[124] Ramani AP, Desai MM, Steinberg AP, et al. Complications of laparoscopic partial nephrectomy in 200 cases. J Urol 2005;173:42-7.

[125] Shikanov S, Lifshitz DA, Deklaj T, Katz MH, Shalhav AL. Predicting collecting system transection at laparoscopic partial nephrectomy: analysis of tumor parameters. J Endourol 2009;23:1863-6.

[126] Weizer AZ, Palella GV, Montgomery JS, Miller DC, Hafez KS. Robotassisted retroperitoneal partial nephrectomy: technique and perioperative results. J Endourol 2011;25:553-7. 
[127] Ginzburg S, Uzzo R, Walton J, et al. Residual parenchymal volume, not warm ischemia time, predicts ultimate renal functional outcomes in patients undergoing partial nephrectomy. Urology 2015;86:300-6.

[128] Kopp RP, Mehrazin R, Palazzi K, Bazzi WM, Patterson AL, Derweesh IH. Factors affecting renal function after open partial nephrectomy-a comparison of clampless and clamped warm ischemic technique. Urology 2012;80:865-70.

[129] Schiavina R, Mari A, Antonelli A, et al. A snapshot of nephronsparing surgery in Italy: a prospective, multicenter report on clinical and perioperative outcomes (the RECORd 1 project). Eur J Surg Oncol J Eur Soc Surg Oncol Br Assoc Surg Oncol 2015;41:346-52.

[130] Kim SH, Joung JY, Seo HK, Lee KH, Chung J. Baseline chronic kidney disease and ischemic method of partial nephrectomy are important factors for the short- and long-term deterioration in renal function for renal cell carcinoma staged T1-T2: a retrospective single center study. BioMed Res Int 2016;2016:5398381.

[131] McClintock TR, Bjurlin MA, Wysock JS, et al. Can selective arterial clamping with fluorescence imaging preserve kidney function during robotic partial nephrectomy? Urology 2014;84:327-34.

[132] Huang J, Chen Y, Dong B, et al. Effect of remote ischaemic preconditioning on renal protection in patients undergoing laparoscopic partial nephrectomy: a 'blinded' randomised controlled trial: remote ischaemic preconditioning and renal protection in patients undergoing LPN. BJU Int 2013;112:74-80.

[133] Yoon YE, Choi KH, Lee KS, et al. Usefulness of the diameter-axialpolar nephrometry score for predicting perioperative parameters in robotic partial nephrectomy. World J Urol 2015;33:841-5.

[134] Parekh DJ, Weinberg JM, Ercole B, et al. Tolerance of the human kidney to isolated controlled ischemia. J Am Soc Nephrol 2013;24:506-17.

[135] Shin TY, Komninos C, Kim DW, et al. A novel mathematical model to predict the severity of postoperative functional reduction before partial nephrectomy: the importance of calculating resected and ischemic volume. J Urol 2015;193:423-9.

[136] Antonelli A, Minervini A, Mari A, et al. TriMatch comparison of the efficacy of FloSeal versus TachoSil versus no hemostatic agents for partial nephrectomy: results from a large multicenter dataset: efficacy of hemostatics for partial nephrectomy. Int J Urol 2015;22:47-52

[137] Lee H, Song BD, Byun S-S, Lee SE, Hong SK. Impact of warm ischaemia time on postoperative renal function after partial nephrectomy for clinical T1 renal cell carcinoma: a propensity scorematched study. BJU Int 2018;121:46-52.

[138] Bhattu AS, Ganpule A, Sabnis RB, Murali V, Mishra S, Desai M. Robot-assisted laparoscopic donor nephrectomy vs standard laparoscopic donor nephrectomy: a prospective randomized comparative study. J Endourol 2015;29:1334-40.

[139] Lane BR, Russo P, Uzzo RG, et al. Comparison of cold and warm ischemia during partial nephrectomy in 660 solitary kidneys reveals predominant role of nonmodifiable factors in determining ultimate renal function. J Urol 2011;185:421-7.

[140] Rini BI, Plimack ER, Takagi T, et al. A phase II study of pazopanib in patients with localized renal cell carcinoma to optimize preservation of renal parenchyma. J Urol 2015;194:297-303.

[141] Brown GA, Matin SF. Laparoscopic partial nephrectomy: experience in 60 cases. J Endourol 2007;21:71-4.

[142] Danzig MR, Ghandour RA, Chang P, et al. Active surveillance is superior to radical nephrectomy and equivalent to partial nephrectomy for preserving renal function in patients with small renal masses: results from the DISSRM registry. J Urol 2015;194:903-9.
[143] DiBLASIO CJ, Snyder ME, Kattan MW, Russo P. Ketorolac: safe and effective analgesia for the management of renal cortical tumors with partial nephrectomy. J Urol 2004;171:1062-5.

[144] El-Ghoneimi A, Valla JS, Steyaert H, Aigrain Y. Laparoscopic renal surgery via a retroperitoneal approach in children. J Urol 1998;160:1138-41.

[145] Hidas G, Kastin A, Mullerad M, Shental J, Moskovitz B, Nativ O. Sutureless nephron-sparing surgery: Use of albumin glutaraldehyde tissue adhesive (BioGlue). Urology 2006;67:697-700.

[146] Abdeldaeim HM, Abou Youssif TM, Abdel Wahab MM, Kotb AF, El Gebaly OF, Mokhless IA. Prospective randomized comparison between cold and warm ischemia in patients with renal insufficiency undergoing partial nephrectomy. Urology 2015;85:862-8.

[147] Hung AJ, Cai J, Simmons MN, Gill IS. "Trifecta" in partial nephrectomy. J Urol 2013;189:36-42.

[148] Gill IS, Kavoussi LR, Lane BR, et al. Comparison of 1,800 laparoscopic and open partial nephrectomies for single renal tumors. J Urol 2007;178:41-6.

[149] Gill IS, Abreu SC, Desai MM, et al. Laparoscopic ice slush renal hypothermia for partial nephrectomy: the initial experience. J Urol 2003;170:52-6.

[150] Gill IS, Kamoi K, Aron M, Desai MM. 800 Laparoscopic partial nephrectomies: a single surgeon series. J Urol 2010;183:34-42.

[151] Jain S, Yates JK, Munver R. Robot-assisted laparoscopic partial nephrectomy for recurrent renal-cell carcinoma in patients previously treated with nephron-sparing surgery. J Endourol 2013;27:309-12.

[152] Zheng J-H, Xu Y-F, Peng B, et al. Retroperitoneal laparoscopic partial nephrectomy for renal-cell carcinoma in a solitary kidney: report of 56 cases. J Endourol 2009;23:1971-4.

[153] Kang N, Niu Y, Zhang J, et al. Intraoperative ultrasonography: a useful tool in retrolaparoscopic nephron-sparing surgery. Urol Int 2012;88:338-42.

[154] Khoder WY, Sroka R, Siegert S, Stief CG, Becker AJ. Outcome of laser-assisted laparoscopic partial nephrectomy without ischaemia for peripheral renal tumours. World J Urol 2012;30:633-8.

[155] Klingler HC, Susani M, Seip R, Mauermann J, Sanghvi N, Marberger MJ. A novel approach to energy ablative therapy of small renal tumours: laparoscopic high-intensity focused ultrasound. Eur Urol 2008;53:810-8.

[156] Link RE, Bhayani SB, Allaf ME, et al. Exploring the learning curve, pathological outcomes and perioperative morbidity of laparoscopic partial nephrectomy performed for renal mass. J Urol 2005;173:1690-4.

[157] Matlaga BR, Zagoria RJ, Woodruff RD, Torti FM, Hall MC, Phase II. trial of radio frequency ablation of renal cancer: evaluation of the kill zone. J Urol 2002;168:2401-5.

[158] Gettman MT, Bishoff JT, Su LM, et al. Hemostatic laparoscopic partial nephrectomy: initial experience with the radiofrequency coagulation-assisted technique. Urology 2001;58:8-11.

[159] Moinzadeh A, Gill IS, Finelli A, Kaouk J, Desai M. Laparoscopic partial nephrectomy: 3-year followup. J Urol 2006;175:459-62.

[160] Nohara T, Fujita H, Yamamoto K, Kitagawa Y, Gabata T, Namiki M. Modified anatrophic partial nephrectomy with selective renal segmental artery clamping to preserve renal function: a preliminary report: new method of nephron-sparing surgery. Int J Urol 2008;15:961-6.

[161] Papalia R, Simone G, Ferriero M, et al. Laparoscopic and robotic partial nephrectomy without renal ischaemia for tumours larger than $4 \mathrm{~cm}$ : perioperative and functional outcomes. World J Urol 2012;30:671-6.

[162] Pettus JA, Sharp DS, Yossepowitch O, et al. Tumor location does not affect long-term renal function after partial nephrectomy. Urology 2007;69:1059-63. 
[163] Pignot G, Méjean A, Bernhard J-C, et al. The use of partial nephrectomy: results from a contemporary national prospective multicenter study. World J Urol 2015;33:33-40.

[164] Hoda MR, Popken G. Surgical outcomes of fluorescence-guided laparoscopic partial nephrectomy using 5-aminolevulinic acidinduced protoporphyrin IX. J Surg Res 2009;154:220-5.

[165] Ray ER, Turney BW, Singh R, Chandra A, Cranston DW, O'Brien TS. Open partial nephrectomy: outcomes from two UK centres. BJU Int 2006;97:1211-5.

[166] Simsek A, Yavuzsan AH, Colakoglu Y, Atar A, Sahin S, Tugcu V. Comparison of robotic and laparoscopic partial nephrectomy for small renal tumours. Arch Ital Urol E Androl 2017;89:93.

[167] Alanee S, Nutt M, Moore A, et al. Partial nephrectomy for T2 renal masses: contemporary trends and oncologic efficacy. Int Urol Nephrol 2015;47:945-50.

[168] Simon J, Bartsch Jr G, Finter F, Hautmann R, de Petriconi R. Laparoscopic partial nephrectomy with selective control of the renal parenchyma: initial experience with a novel laparoscopic clamp. BJU Int 2009;103:805-8.

[169] Thompson RH, Leibovich BC, Lohse CM, Zincke H, Blute ML. Complications of contemporary open nephron sparing surgery: a single institution experience. J Urol 2005;174:855-8.

[170] Tuğcu V, Şener NC, Şahin S, Yavuzsan AH, Akbay FG, Apaydın S. Robot-assisted kidney transplantation: comparison of the first 40 cases of open vs robot-assisted transplantations by a single surgeon. BJU Int 2018;121:275-80.

[171] Wright JL, Porter JR. Laparoscopic partial nephrectomy: comparison of transperitoneal and retroperitoneal approaches. J Urol 2005;174:841-5.

[172] Zorn KC, Gong EM, Mendiola FP, et al. Operative outcomes of upper pole laparoscopic partial nephrectomy: comparison of lower pole laparoscopic and upper pole open partial nephrectomy. Urology 2007;70:28-34.

[173] Yadav K, Aggarwal S, Guleria S, Kumar R. Comparative study of laparoscopic and mini-incision open donor nephrectomy: have we heard the last word in the debate? Clin Transplant 2016;30:328-34.

[174] Funahashi Y, Kato M, Yoshino Y, Fujita T, Sassa N, Gotoh M. Comparison of renal ischemic damage during laparoscopic partial nephrectomy with artery-vein and artery-only clamping. J Endourol 2014;28:306-11.

[175] Ruan Y, Wang X, Wang K, Zhao Y, Xia S, Xu D. Clinical evaluation and technical features of three-dimensional laparoscopic partial nephrectomy with selective segmental artery clamping. World J Urol 2016;34:679-85.

[176] Zorn KC, Gong EM, Orvieto MA, et al. Comparison of laparoscopic radical and partial nephrectomy: effects on long-term serum creatinine. Urology 2007;69:1035-40.
[177] Dols LFC, Kok NFM, Terkivatan T, et al. Hand-assisted retroperitoneoscopic versus standard laparoscopic donor nephrectomy: HARP-trial. BMC Surg 2010;10:11.

[178] Mir MC, Pavan N, Parekh DJ. Current paradigm for ischemia in kidney surgery. J Urol 2016;195:1655-63.

[179] Kim SP, Campbell SC, Gill I, et al. Collaborative review of risk benefit trade-offs between partial and radical nephrectomy in the management of anatomically complex renal masses. Eur Urol 2017;72:64-75.

[180] Minervini A, Carini M, Uzzo RG, Campi R, Smaldone MC, Kutikov A. Standardized reporting of resection technique during nephronsparing surgery: the surface-intermediate-base margin score. Eur Urol 2014;66:803-5.

[181] Alenezi A, Mottrie A, Novara G, Karim O, Al-Buheissi S. Zero ischaemia partial nephrectomy: a call for standardized nomenclature and functional outcomes. Nat Rev Urol 2016;13:674.

[182] Laganosky DD, Filson CP, Master VA. Surgical margins in nephron-sparing surgery for renal cell carcinoma. Curr Urol Rep 2017; 18:8.

[183] Bensalah K, Pantuck AJ, Rioux-Leclercq N, et al. Positive surgical margin appears to have negligible impact on survival of renal cell carcinomas treated by nephron-sparing surgery. Eur Urol 2010;57:466-73.

[184] Shah PH, Moreira DM, Okhunov Z, et al. Positive surgical margins increase risk of recurrence after partial nephrectomy for high risk renal tumors. J Urol 2016;196:327-34.

[185] Dong W, Wu J, Suk-Ouichai C, et al. Devascularized parenchymal mass associated with partial nephrectomy: predictive factors and impact on functional recovery. J Urol 2017;198:787-94.

[186] Bertolo RG, Zargar H, Autorino R, et al. Estimated glomerular filtration rate, renal scan and volumetric assessment of the kidney before and after partial nephrectomy: a review of the current literature. Minerva Urol E Nefrol Ital J Urol Nephrol 2017;69:539-47.

[187] ClinicalTrials.gov. Warm ischemia or cold ischemia during surgery in treating patients with stage I kidney cancer-full text view. n.d. https://clinicaltrials.gov/ct2/show/NCT00743236.

[188] ClinicalTrials.gov. CLamp vs off clamp kidney during partial nephrectomy-full text view. n.d. https://clinicaltrials.gov/ct2/show/ NCT02287987.

[189] ClinicalTrials.gov. RFR change of precise segmental versus complete renal arterial clamping during LPN for clinical T1 RCC-full text view. n.d. https://clinicaltrials.gov/ct2/show/ NCT03259477.

[190] ClinicalTrials.gov. Renal hypothermia during partial nephrectomy-full text view. n.d. https://clinicaltrials.gov/ct2/show/ NCT01529658. 